\title{
Te doping of GaAs using diethyl-tellurium
}

\author{
M. Kamp, a) G. Mörsch, J. Gräber, and H. Lüth \\ Institut für Schicht-und Ionentechnik, Forschungszentrum Jülich, 52425 Jülich, Germany
}

(Received 20 January 1994; accepted for publication 18 April 1994)

The performance of the gaseous precursor diethyl-tellurium (DETe) for $n$-type doping of GaAs is studied. We report on both the properties of the molecular source DETe as well as on the suitability of the dopant element tellurium. Te is found to be an excellent dopant, comparable to $\mathrm{Si}$ in the lower-doping regime and superior at highest-doping levels. DETe reveals itself to be a convenient and reproducible doping source. At substrate temperatures above $540^{\circ} \mathrm{C}$, dopant desorption (most probably $\mathrm{Te}$ ) is observed which limits its applications. Memory effects after doping up to the mid $10^{18} \mathrm{~cm}^{-3}$ range can be eliminated. At still higher-doping levels an optimized technique limits unintentional background carrier concentrations in subsequent layers to the $10^{14} \mathrm{~cm}^{-3}$ range.

Today, adyanced device technology requires dopants capable of producing carrier concentrations over a wide range, combined with high carrier mobilities, excellent controllability, low diffusion, and low self compensation, especially at the highest-doping levels. In the most important III-V semiconductor systems [e.g., GaAs/AlGaAs, InP/GaInAs(P)], silicon ( $\mathrm{Si}$ ) is widely used for $n$-type doping. Good results were reported for molecular beam epitaxy (MBE), metalorganic MBE (MOMBE), and metalorganic vapor phase epitaxy (MOVPE) grown material using Si from effusion cells and gaseous precursors, respectively. Although the properties of Si are sufficient for many of today's applications, reduced diffusion and higher-doping levels would improve the performance of some devices, would allow the realization of new device structures, and would permit interesting fundamental studies. Furthermore, Si is not an ideal dopant since it suffers from a significant self compensation at free-carrier concentrations above $5 \times 10^{18} \mathrm{~cm}^{-3}$ and a high segregation tendency which is, for example, a limitation for the use of $\mathrm{Si}$ for delta doping. ' The group VI element tellurium (Te) is not as well investigated as $\mathrm{Si}$, but existing data suggest that at least in $\mathrm{GaAs}$ this element is superior to silicon. At typical growth temperatures, Te has a significantly lower diffusivity than $\mathrm{Si}$ (i.e., Te: $D \sim 3 \times 10^{-23} \mathrm{~cm}^{-2} / \mathrm{s}, \mathrm{Si}: 2 \times 10^{-16}<D<2 \times 10^{-20}$ $\mathrm{cm}^{-2} / \mathrm{s}$ depending on doping level, $T=600{ }^{\circ} \mathrm{C}^{2}$ ) and provides a donor with a lower activation energy in AlGaAs. ${ }^{3}$ Additionally, employing Te allows the maximum free-carrier concentration to be extended up to $2 \times 10^{19} \mathrm{~cm}^{-3}$, about two to three times higher than is possible with Si. Due to these advantages, Te has already been investigated as a dopant in liquid phase epitaxy $\left(\mathrm{LPE}^{5}\right)$ and MBE. ${ }^{6}$ Despite the verification of its excellent behavior Te has not replaced $\mathrm{Si}$ as the most popular MBE donor element.

Decisive for this are most likely technical problems which occur for the evaporation of Te from Knudsen cells. $\mathrm{Te}$, which evaporates as $\mathrm{Te}_{2}$ molecules, has a vapor pressure of $1 \times 10^{-5}$ Torr at $250^{\circ} \mathrm{C}$, and is therefore incompatible with usual bake-out procedures of effusion cells and growth chambers in conventional MBE.

In the past the superior doping behavior has spurred several attempts to make Te applicable to MBE. These include

a) Present address: IBM Research Division, Zurich Research Laboratory, Säumerstr. 4, CH-8803 Rüschlikon, Switzerland. surface-exchange doping with $\mathrm{PbTe},{ }^{4}$ combined doping using $\mathrm{SnTe},{ }^{7}$ and the coevaporation of GaTe. ${ }^{8}$ All of these approaches have revealed certain drawbacks which prevented them from gaining widespread use.

This communication deals with the use of DETe (diethyl-tellurium, $\left.\mathrm{Te}\left(\mathrm{C}_{2} \mathrm{H}_{5}\right)_{2}\right)$ as a doping precursor. DETe was chosen since it combines the above-mentioned advantages of Te with the benefits of gaseous precursors.

The convenient handling and advantageous controllability of gaseous precursors makes them attractive for industrial applications. The use of leak valves provides a fast and accurate control of the dopant fluxes which allows convenient realization of nearly arbitrary doping profiles. Excellent long-term stability and high reproducibility even after exchange of the particular source are provided. Additionally, the "cold" injector $\left(\sim 100^{\circ} \mathrm{C}\right)$ avoids further hot spots in the growth equipment.

The physical and chemical properties of DETe make it an attractive source for Te. DETe is a liquid up to $136 .^{\circ} \mathrm{C}$. It has a relatively low reactivity (stable to air and water) and a vapor pressure $\left(12\right.$ Torr at $\left.30^{\circ} \mathrm{C}^{9}\right)$ which is sufficient for MOMBE applications even without the use of a carrier gas. Up to now DETe has successfully been used as a dopant for GaAs in MOVPE. ${ }^{10,11}$ Additionally, a very preliminary study about its use in MOMBE growth of GaAs and InP has also been reported. ${ }^{12}$

All experiments presented in this communication were carried out using MOMBE as growth technique. Despite this, the authors expect that the results are not limited to MOMBE, but are valid for conventional MBE too.

Precracked $\mathrm{AsH}_{3}$ was used together with TEGa $\left[\mathrm{Ga}\left(\mathrm{C}_{2} \mathrm{H}_{5}\right)_{3}\right]$ for the growth of GaAs in a modified Varian GEN II MOMBE system. All source materials $\left(\mathrm{AsH}_{3}, \mathrm{TEGa}\right.$, and DETe) were injected into the chamber by a modified pressure controlled flow system using direct distillation. Therefore background pressure in the growth chamber was below $5 \times 10^{-3} \mathrm{~Pa}$ during growth. Substrates were semiinsulating, exactly oriented [100] GaAs wafers. Growth temperature was determined by an infrared pyrometer.

The carrier concentrations were determined by Hall, electrochemical CV (ECV), and differential Hall measurements, respectively. Secondary-ion-mass spectroscopy (SIMS) was used to examine the tellurium depth profile.

The DETe was introduced into the growth chamber 


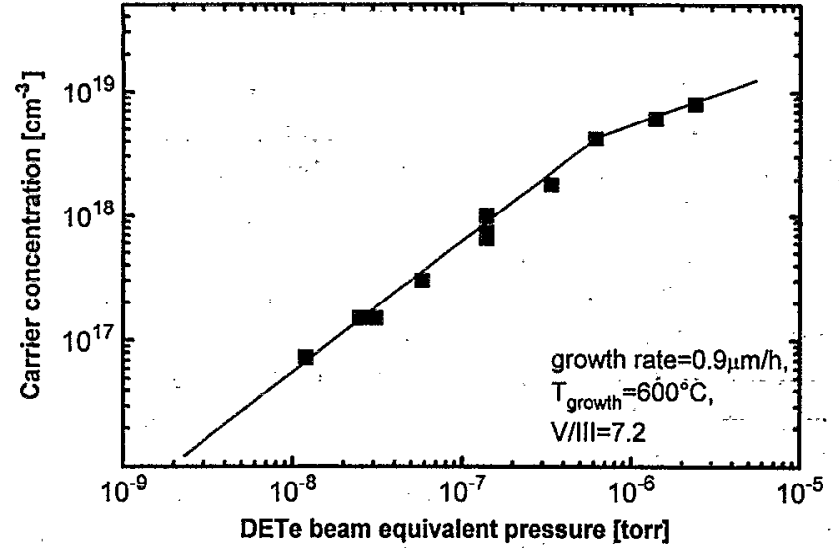

FIG. 1. Free-electron concentration as a function of DETe beam pressure.

through the group III alkyl low-temperature injector. Co injection together with TEGa was chosen to take advantage of the expected perfect homogeneous distribution of the dopant relative to the source material.

We observed a controllable doping range between $4 \times 10^{16}$ and $2 \times 10^{19} \mathrm{~cm}^{-3}$, where the lower limit was only determined by the leak rate of the particular control valve. Over this whole range, no deleterious effect from the DETe supply on the mirrorlike morphology is observable.

Below carrier concentrations of $6 \times 10^{18} \mathrm{~cm}^{-3}$, the freeelectron concentration is directly proportional to the DETe beam equivalent pressure, whereas at higher fluxes the carrier concentrations exhibit a second regime with a slightly lower slope (Fig. 1). This behavior could be caused by two different mechanisms: a change in the doping behavior (e.g., electrical activation) presuming a constant incorporation or a change in incorporation behavior presuming that the doping characteristics of the Te are unchanged.

To clarify the observed dependence, SIMS measurements were carried out on samples with different doping levels grown at different temperatures (Fig. 2). These data reveal clearly that saturation occurs. Changes in $\mathrm{Te}$ incorporation are found to play only a minor role, whereas the elcctrical activation of the Te decreases significantly with higher-doping levels. The onset of the change in the doping properties depends on growth temperature. At $610^{\circ} \mathrm{C}$, the electrical activation of the incorporated $\mathrm{Te}$ atoms decreases above carrier concentrations of $4 \times 10^{18} \mathrm{~cm}^{-3}$. Te incorporated during growth at $540^{\circ} \mathrm{C}$ reveals a constant electrical activation up to carrier concentrations of $7 \times 10^{18} \mathrm{~cm}^{-3}$. This temperature dependence of the change in the electrical behavior of the incorporated Te suggests the presence of kinetic limitations in the involved mechanism.

In addition to a wide doping range, a suitable dopant hás to provide good carrier mobilities over the entire range of doping. Te fulfills these requirements as can be deduced by a comparison of the measured mobilities (Fig. 3) with the expected mobilities for Si doping according to the empirical Hilsum formula ${ }^{13}$ (dashed curve).

For doping levels above $5 \times 10^{17} \mathrm{~cm}^{-3}$, one can deduce a compensation ratio of $\gamma=\left(N_{D}-N_{A}\right) /\left(N_{D}+N_{A}\right) \approx 1$ according to Rhode, ${ }^{14}$ whereas at free-carrier concentrations below

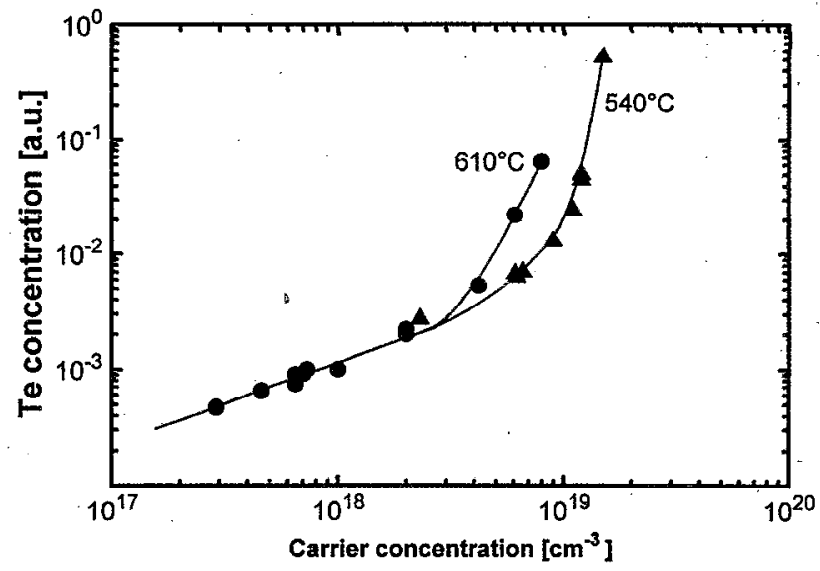

FIG. 2. Te concentration as a function of free-electron concentration.

$1 \times 10^{17} \mathrm{~cm}^{-3}$, the mobilities reveal a significant compensation of $\gamma \approx 2.5$, which corresponds to an acceptor level of $\sim 1.5-2 \times 10^{16} \mathrm{~cm}^{-3}$. Here, it has to be pointed out that this quantitative interpretation is of limited accuracy (since it relies on room-temperature measurements), but is supported by the very few available $77 \mathrm{~K}$ data $\left(\mu_{77}=7600 \mathrm{~cm}^{2} / \mathrm{V} \mathrm{s}\right.$ and $\mu_{77}=7200 \mathrm{~cm}^{2} / \mathrm{V} \mathrm{s}$ for $n=2 \times 10^{16} \mathrm{~cm}^{-3}, n=4 \times 10^{16}$ $\mathrm{cm}^{-3}$, respectively).

The observed change in the compensation ratio is indicative of negligible carbon incorporation from the DETe. Carbon incorporated from DETe would be proportional to DETe pressure (i.e., the carrier concentration), leading to a constant $\mathrm{Te} / \mathrm{C}$ ratio (i.e., compensation ratio) which was not found. In fact, the observed acceptor level corresponds exactly to the expected doping level caused by $\mathrm{C}$ incorporated from the TEGa. Under these particular growth conditions (i.e., growth temperature $600^{\circ} \mathrm{C}$ ) a background acceptor level of $\sim 2 \times 10^{16} \mathrm{~cm}^{-3}$ is expected, which is in excellent agreement with the obtained results.

In addition to the discussed electrical properties, the growth temperature dependence of the carrier concentration has to be investigated (Fig. 4). Here, free-carrier concentrations are proportional to the incorporated $\mathrm{Te}$ atoms since

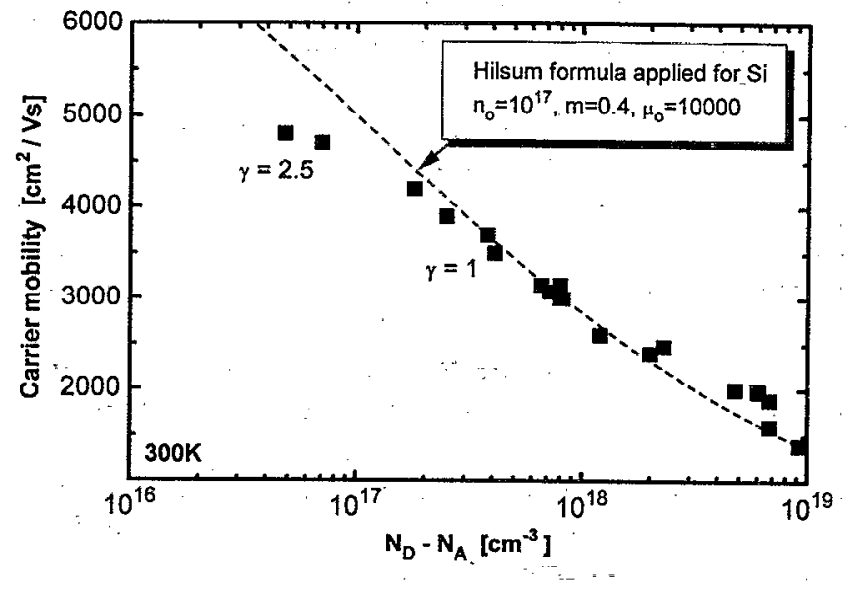

FIG. 3. Carrier mobility vs free-electron concentration. 


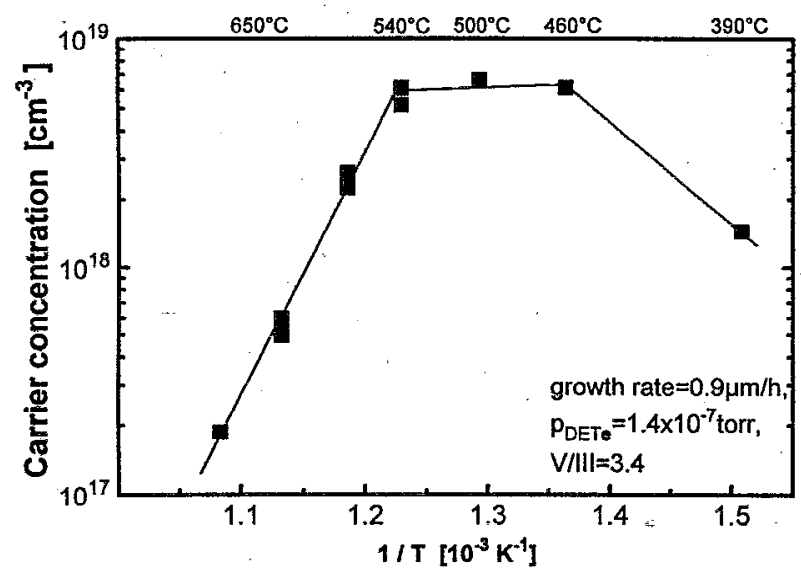

FIG. 4. Carrier concentration vs reciprocal growth temperature.

electrical activation is constant at this doping levels (see Fig. 2). Three different regimes of the $\mathrm{Te}$ incorporation can clearly be distinguished and interpreted as decomposition limited, supply limited, and desorption limited regime.

At temperatures below $\sim 450^{\circ} \mathrm{C}$ the incorporation of $\mathrm{Te}$ is limited by the DETe decomposition at the surface which is in good agreement with the reported pyrolytical decomposition of DETe at temperatures above $410^{\circ} \mathrm{C}$.

Between 450 and $540^{\circ} \mathrm{C}$, the electron concentration is nearly independent on growth temperature indicating a supply limited regime. In this regime the incorporation efficiency of Te from DETe is quite high compared to other gaseous dopant sources..$^{12}$ Above $540^{\circ} \mathrm{C}$ the net electron concentration decreases exponentially with increasing temperature, indicating a desorption of an unknown Te species. Since the onset of this desorption regime is equal to results observed from experiments using either elemental $\mathrm{Te}^{15}$ or $\mathrm{SnTe},{ }^{7}$ the desorbing species is expected to be elemental Te.

The observed temperature-dependent incorporation of $\mathrm{Te}$ has a strong effect on its suitability. The supply limited temperature range is compatible with usual MOMBE growth temperatures for GaAs and InP, therefore DETe reveals good suitability for these purposes. Indeed, besides the data presented here for the GaAs system, first results in InP doping with DETe are also very promising and doping levels up to $5 \times 10^{19} \mathrm{~cm}^{-3}$ have already been demonstrated. ${ }^{12}$

However, above $540^{\circ} \mathrm{C}$, the described Te desorption has to be considered as a drawback. It reduces the doping levels for a given DETe beam pressure and it increases the risk of a memory effect. This is especially undesirable if, as in the case of $\mathrm{Te}$, the desorbing species has a high vapor pressure at temperatures which could easily exist in the vicinity of effusion cells, ion gauges, etc.

Even in the supply limited regime, a significant portion of the supplied $\mathrm{Te}$ (or one of its partly decomposed species) is obviously not incorporated into the GaAs. Therefore, special attention has to be paid to possible memory effects from the desorbing species when they decompose at hot surface. To check for unintentional background doping, undoped samples have been grown using conditions optimal for Te incorporation directly after admitting high DETe fluxes $\left(p_{\text {DETe }}=2.4 \times 10^{-6}\right.$ Torr). These layers reveal unintentional background electron concentrations up to the high $10^{16} \mathrm{~cm}^{-3}$ range. However, these memory effects can strongly be reduced to the low $10^{14} \mathrm{~cm}^{-3}$ range by limiting the doping level to $1 \times 10^{19} \mathrm{~cm}^{-3}$ and applying moderate outgassing of the injectors and substrate heater.

In summary, DETe allows higher carrier concentrations to be obtained in GaAs than Si. Since the maximum doping level for DETe is at least twice as high as for $\mathrm{Si}$ (with comparable mobilities), conductivity can also be twice as high, making DETe very attractive for applications in highly doped contact or transistor base layers. In the $10^{17} \mathrm{~cm}^{-3}$ range carrier mobilities are as good as for $\mathrm{Si}$, whereas for lowerdoping levels an evaluation is not possible since the mobilities have already been limited by $\mathrm{C}$ incorporation from the TEGa.

DETe has been proven to be a convenient and wellsuited dopant source for GaAs. It allows an easy control of the free-electron concentration and yields layers with excellent electrical characteristics. However, memory effects have been found, but can be reduced to the $10^{14} \mathrm{~cm}^{3}$ range by proper handling even after doping up to $1 \times 10^{19} \mathrm{~cm}^{-3}$. At substrate temperatures above $540^{\circ} \mathrm{C}$ significant desorption occurs (most probably elemental $\mathrm{Te}$ ), reducing the suitability of DETe at higher temperatures. Even here excellent doping results can still be obtained, but one has to be aware that the observed desorption further increases the risk of memory effects. Therefore, DETe appears to be especially useful for doping at lower growth temperatures where Te desorption was observed to be negligible. Keeping this in mind, DETe should also be very interesting for the doping of InP where growth temperatures arc usually below $540{ }^{\circ} \mathrm{C}$ and doping levels of $5 \times 10^{19} \mathrm{~cm}^{-3}$ can be reached.

The authors are indebted to $\mathrm{K}$. Nicoll for technical assistance. Additionally, they would like to thank J. Herion and H. Siekmann for SIMS measurements.

\footnotetext{
${ }^{1}$ See, for example, K. Koehler, P. Ganser, and M. Maier, J. Cryst. Growth 127, 720 (1993).

${ }^{2} \mathrm{~J}$. W. Mayer and S. S. Lau, Electronic Materials Science for Integrated Circuits in Si and GaAs (MacMillan, New York, 1990).

${ }^{3}$ A. J. Spring Thorpe, F. D. King, and A. Becke, J. Electron. Mater. 4, 101 (1975).

${ }^{4}$ J. De-Sheng, Y. Makita, K. Ploog, and H. J. Queisser, J. Appl. Phys. 53, 999 (1982).

${ }^{5}$ H. C. Casey, M. B. Panish, and K. B. Wolfstirn, J. Phys. Chem. Solids 32, 571 (1971).

${ }^{6}$ J. R. Arthur, Surf. Sci. 43, 449 (1974).

${ }^{7}$ D. M. Collins and J. N. Miller, J. Appl. Phys. 53, 3010 (1982).

${ }^{8}$ G. W. Turner, S. J. Eglash, and A. J. Strauss, J. Vac. Sci. Technol. B 11 , 864 (1993).

${ }^{9} \mathrm{G}$. B. Stringfellow, Organometallic Vapor-Phase Epitaxy: Theory and Practice (Academic, San Diego, 1989).

${ }^{10}$ S. Z. Sun, E. A. Armour, K. Zheng, and C. F. Schaus, J. Cryst. Growth 113, 103 (1991).

${ }^{11}$ Y. M. Houng and T. S. Low, J. Cryst. Growth 77, 272 (1986).

${ }^{12}$ M. Weyers, J. Musolf, D. Marx, A. Kohl, and P. Balk, J. Cryst. Growth 105, 383 (1990).

${ }^{13} \mathrm{C}$. Hilsum, Electron. Lett. 10, 259. (1974).

${ }^{14}$ D. L. Rode, in Semiconductors and Semimetals 10, edited by R. K. Willardson and A. C. Beer (Academic, New York, 1975).

${ }^{15}$ C. E. C. Wood, in The Technology and Physics of Molecular Beam Epitaxy, edited by E. H. C. Parker (Plenum, New York, 1985), p. 61.
} 
Journal of Applied Physics is copyrighted by the American Institute of Physics (AIP). Redistribution of journal material is subject to the AIP online journal license and/or AIP copyright. For more information, see http://ojps.aip.org/japo/japcr/jsp

Copyright of Journal of Applied Physics is the property of American Institute of Physics and its content may not be copied or emailed to multiple sites or posted to a listserv without the copyright holder's express written permission. However, users may print, download, or email articles for individual use. 